\title{
A Meta-Analysis of Long- Versus Short-Acting Phosphodiesterase 5 Inhibitors: Comparing Combination Use With a-Blockers and a-Blocker Monotherapy for Lower Urinary Tract Symptoms and Erectile Dysfunction
}

\author{
Hoon Choi ${ }^{1}$, Hyun Jung Kim², Jae Hyun Bae ${ }^{1}$, Jae Heon Kim³ ${ }^{3}$ Du Geon Moon ${ }^{1}$, Jun Cheon ${ }^{1}$, Jeong-Kyun Yeo \\ ${ }^{1}$ Department of Urology, Korea University Ansan Hospital, Korea University College of Medicine, Ansan, Korea \\ ${ }^{2}$ Institute for Evidence-Based Medicine, The Korean Branch of Australasian Cochrane Center, Department of Preventive Medicine, Korea University College \\ of Medicine, Seoul, Korea \\ ${ }^{3}$ Department of Urology, Soonchunhyang University Seoul Hospital, Soonchunhyang University School of Medicine, Seoul, Korea \\ ${ }^{4}$ Department of Urology, Inje University Seoul Paik Hospital, Inje University College of Medicine, Seoul, Korea
}

\begin{abstract}
Purpose: Combination therapy with an $\alpha$-1-adrenergic blocker and phosphodiesterase type 5 inhibitors (PDE5Is) has shown improvements in lower urinary tract symptoms (LUTS) with negligible side effects. Nonetheless, decisive advantages in symptom improvement were insufficient, and there were no clinical differences between long- or short-acting PDE5Is in combination with combination medication.

Methods: To review the studies on $\alpha$-1-adrenergic blocker monotherapy and combination therapy with long vs. short-acting PDE5Is in their use in LUTS and erectile dysfunction (ED). A search of the MEDLINE, Embase, Cochrane Library, and KoreaMed databases was conducted from 2000 to 2014 using combinations of the relevant terms. Among the 323 relevant references discovered, 10 were selected for meta-analysis. The data showed that 616 men received combination therapy (PDE5Is with $\alpha$-1-adrenergic blockers) or $\alpha$-1-adrenergic blocker monotherapy.

Results: Meta-analysis of the combination therapy showed it was more effective than $\alpha$-blockers in improving symptoms, with a mean International Prostrate Symptom Score change difference of -1.93 while those of the long- vs. short-acting PDE5I were -2.12 vs. -1.70 . Compared to maximum flow rate (Qmax) value with monotherapy, the Qmax increased more with the combination therapy (mean difference of 0.71 ) while change values were 0.14 and 1.13 for the long- and short-acting PDE5Is, respectively. Residual urine decreased more with the combination therapy than it did with $\alpha$-1-adrenergic blocker monotherapy with a mean difference of -7.09 while the mean residual urine change values for long- vs. short-acting PDE5Is were -18.83 vs. -5.93 . The International Index of Erectile Function value increased by 3.99, 2.85, and 4.85 following combination therapy, and therapy with long- and short-acting PDE5Is.

Conclusions: Our meta-analysis suggests that PDE5Is can significantly improve LUTS in men with benign prostatic hyperplasia/ED. Furthermore, combination PDE5I and $\alpha$-1-adrenergic blocker could be a more effective treatment than $\alpha$-1adrenergic blocker monotherapy, and the differences between long and short-acting agents were minimal.
\end{abstract}

\section{Keywords: Prostatic Hyperplasia; Lower Urinary Tract Symptoms; Phosphodiesterase 5 Inhibitors}

- Grant Support: This work was supported by the National Research Foundation of Korea (NRF) grant funded by the Korea government (MSIP) (No. 2011-0020128).

- Conflict of Interest: No potential conflict of interest relevant to this article was reported.

Corresponding author: Jeong-Kyun Yeo (iD http://orcid.org/0000-0001-5027-3451 Department of Urology, Inje University Seoul Paik Hospital, Inje University College of Medicine, 9 Mareunnae-ro, Jung-gu, Seoul 04551, Korea E-mal: yeoluvk@gmail.com / Tel +82-2-2270-0078 / Fax + 82-2-2270-0226 -Hoon Choi iD http://orcid.org/0000-0002-8481-8103 Submitted: November 30, 2015 / Accepted after revision: December 14, 2015
This is an Open Access article distributed under the terms of the Creative Commons Attribution Non-Commercial License (http://creativecommons.org/licenses/by-nc/3.0/) which permits unrestricted non-commercial use, distribution, and reproduction in any medium, provided the original work is properly cited. 


\section{INTRODUCTION}

Lower urinary tract symptoms (LUTS) and sexual dysfunction are common urologic diseases in older males. The incidence of LUTS increases with age and is prevalent in more than half of men who are 50 years or older [1,2]. The pathogenesis of benign prostatic hyperplasia (BPH)-LUTS is complicated, only partially understood, and involves bladder/prostate afferent nerve activity, feeding vessel ischemia, and various physiologic pathways [3]. Currently, $\alpha$-blockers and 5a-reductase inhibitors are effective and widely accepted treatment choices for $\mathrm{BPH}$. However, they are associated with side effects such as dizziness, hypotension, and sexual dysfunction with limited clinical efficacy [4].

Therefore, there is a continuing need for more advances in developing BPH medications that cover the complex pathophysiology of LUTS.

In 1998, phosphodiesterase type 5 inhibitors (PDE5Is) were first approved for the treatment of erectile dysfunction (ED). The mechanism of action of PDE5Is involves increasing the levels of the second messenger, cyclic guanosine monophosphate (cGMP), which induces penile erection through smooth muscle relaxation [5]. Theoretically, PDE5Is can increase the level of nitric oxide (NO) in smooth muscle, which mediates smooth muscle relaxation in the corpus cavernosum, thereby facilitating penile erection. Additionally, $\mathrm{NO}$ can relax smooth muscles of voiding-related urological organs such as the bladder neck and prostate, eventually relieving BPH-related LUTS $[3,5]$.

The American Urological Association guidelines recommend $a$-adrenergic blockers as the most rapid, effective therapy for the management of LUTS [6]. We can infer that PDE5Is affect LUTS through various mechanisms other than $\alpha$-adrenergic receptor blockade and therefore, combination therapy with a-blockers and PDE5Is would be expected to offer better outcomes than $\alpha$-blocker monotherapy. However, there is a lack of definite evidence supporting this hypothesis. Daily low-dose (5 $\mathrm{mg}$ ) tadalafil was first approved for the management of LUTS. The long half-life and effective serum concentration of tadalafil make it theoretically suitable for use as a daily medication for LUTS [3]. It is important to differentiate the clinical characteristic of long- and short-acting PDE5Is prior to their combination use with $\alpha$-blockers. Therefore, the goal of the current systematic review is to summarily compare the effects of $\alpha$-blockers plus short- or long-acting PDE5Is vs. a blocker monotherapy. In ad- dition, a meta-analysis of the data presently available in the literature on the combination use of PDE5Is in LUTS including a subgroup analysis of the half-life of PDE5Is will be conducted.

\section{MATERIALS AND METHODS}

We conducted an inclusive exploration based on multidatabase electronic literature searches to classify relevant clinical research study articles published between January 1990 and December 2014. Literature searches of MEDLINE, Embase, Cochrane library, and the KoreaMed databases were performed without any limitations on the study design and language. The keywords used in the search were standardized medical terminology developed to index articles for each publication source (MEDLINE, MeSH; Embase, Emtree) and included lower urinary tract symptoms, LUTS, benign prostatic hyperplasia, $\mathrm{BPH}$, sildenafil, tadalafil, vardenafil, udenafil, and mirodenafil. The literature search process was based on the table suggested by the Cochrane Collaboration [7]. When necessary, an article title and abstract were excluded if they did not meet the selection criteria set to achieve our study purpose of comparing the combination use of PDE5Is and $\alpha$-blockers vs. $\alpha$-blocker monotherapy. Individual documents were evaluated using each of the tools and were subsequently separated according to the study design.

The primary monitoring of the electronic databases to classify potential studies for inclusion based on titles and abstracts was performed by two independent authors (H.C. and J.H.B.). If relevant data were lacking, both authors assessed the whole text of the affected study for a clear interpretation, and the final decision was made by another independent author (J.K.Y.). The included data were subsequently crosschecked carefully to ensure there were no overlapping data and ascertained the integrity of the meta-analysis.

The bias risk of the selected studies was evaluated. Furthermore, the differences in opinion of the monitoring authors regarding the suitability of selected studies during the extraction process were debated and decided. The class of the studies were determined using the accessible recent standards of trial reporting forms and related parameters including randomization methods, allocation concealment, blinding of assessment, and dropout criteria $[8,9]$.

The studies selected for inclusion in our review were randomized clinical trials on the combination use of short- or long-acting PDE5Is plus $\alpha$-blockers vs. $\alpha$-blocker monotherapy 
for LUTS with BPH. The statistical heterogeneity was assessed using the chi-square test and $\mathrm{I}^{2}>70 \%$ were considered to signify statistical heterogeneity. All analyses were performed using the RevMan (version 5.3; Cochrane's Informatics \& Knowledge Management Department) and the SPSS ver. 17.0 (SPSS Inc., Chicago, IL, USA). All tests were two-sided and P-values $<0.05$ were considered statistically significant. Weighted mean differences between the experimental and control groups, as well as 95\% confidence intervals (Cls), were calculated for continuous variables. An expert statistician performed all the statistical analyses.

\section{RESULTS}

A full comprehensive flow chart for the study enrollment decision is shown in Fig. 1. The preliminary sorting process found 935 articles in the electronic databases: 576, 208, 131, and 20 from Embase, MEDLINE, Cochrane, and KoreaMed, respectively. Next, 146 studies were excluded for overlapping or being searched in more than one database. Then, the screening of paper titles and abstracts yielded 466 studies that did not meet the inclusion criteria and therefore, were excluded. Subsequently, 323 papers were meticulous reviewed, and 313 were excluded because of a lack of relevance to our study topic (298) or an inadequate study design (15) and 10 studies were finally selected.

Table 1 shows the included trials in the meta-analysis. The duration of treatment ranged from 4 to 12 weeks. There were 292 cases each of the combination therapy and $\alpha$-1-adrenergic blocker monotherapy. Fig. 2 shows the efficacy differences in symptom improvements. The meta-analysis revealed that the combination therapy was more effective than the a-blocker was in improving symptoms, and the mean IPSS change difference was -1.93 (95\% CI, -2.54 to -1.32 ). In addition, the differences based on acting durations showed mean International Prostrate Symptom Score (IPSS) changes in the long- vs. short-acting

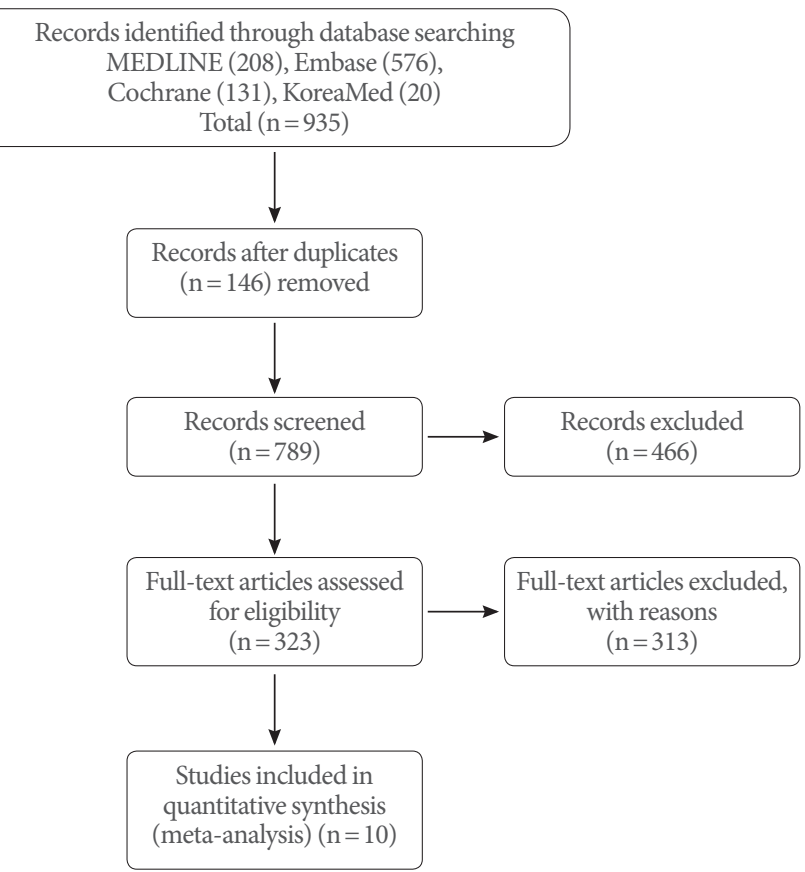

Fig. 1. Flowchart of literature search and protocol completion for studies on long- vs. short-acting phosphodiesterase type 5 inhibitors combined with $\alpha 1$-adrenergic-blocker vs. $\alpha$-adrenergic blocker alone.

Table 1. Individual research information included in meta-analysis

\begin{tabular}{|c|c|c|c|c|c|c|}
\hline Study & $\begin{array}{l}\text { Study duration } \\
\text { (wk) }\end{array}$ & Combination of PDE5Is plus a-blocker & No. & Alpha-blocker alone & No. & $\begin{array}{l}\text { Jadad } \\
\text { score }\end{array}$ \\
\hline Kaplan et al. (2007) [19] & 12 & Alfuzosin 10 mg/day + sildenafil 25 mg/day & 15 & Alfuzosin $10 \mathrm{mg} /$ day & 15 & 3 \\
\hline Bechara et al. (2008) [20] & 6 & Tamsulosin $0.4 \mathrm{mg} /$ day + tadalafil $20 \mathrm{mg} /$ day & 15 & Tamsulosin $0.4 \mathrm{mg} /$ day & 15 & 3 \\
\hline Liguori et al. (2009) [21] & 12 & Alfuzosin $10 \mathrm{mg} /$ day + tadalafil $20 \mathrm{mg}$ on alternative day & 23 & Alfuzosin $10 \mathrm{mg} /$ day & 22 & 3 \\
\hline Tuncel et al. (2010) [22] & 8 & Tamsulosin $0.4 \mathrm{mg}+$ sildenafil $25 \mathrm{mg} 4$ times/wk & 20 & Tamsulosin $0.4 \mathrm{mg} /$ day & 20 & 2 \\
\hline Gacci et al. (2012) [23] & 12 & Tamsulosin $0.4 \mathrm{mg}$ + vardenafil $10 \mathrm{mg}$ & 30 & Tamsulosin $0.4 \mathrm{mg}$ mg/day & 30 & 3 \\
\hline Ozturk et al. (2012) [24] & 12 & Alfuzosin $10 \mathrm{mg} /$ day + sildenafil $25 \mathrm{mg} /$ day & 50 & Alfuzosin 10 mg/day & 50 & 3 \\
\hline Regadas et al. (2013) [25] & 4 & Tamsulosin $0.4 \mathrm{mg}+$ tadalafil $5 \mathrm{mg} /$ day & 20 & Tamsulosin $0.4 \mathrm{mg} /$ day & 20 & 3 \\
\hline Abolyosr et al. (2013) [26] & 16 & Doxazosin 2 mg + Sildenafil 50 mg/day & 50 & Doxazosin 2 mg/day & 50 & 3 \\
\hline Kumar et al. (2014) [27] & 12 & Alfuzosin $10 \mathrm{mg} /$ day + tadalafil $10 \mathrm{mg} /$ day & 25 & Alfuzosin $10 \mathrm{mg} /$ day & 25 & 2 \\
\hline Singh et al. (2014) [28] & 12 & Tamsulosin $0.4 \mathrm{mg} /$ day + tadalafil $10 \mathrm{mg} /$ day & 44 & Tamsulosin 0.4 mg/day & 45 & 3 \\
\hline Total & 4 to 12 & & 292 & & 292 & \\
\hline
\end{tabular}




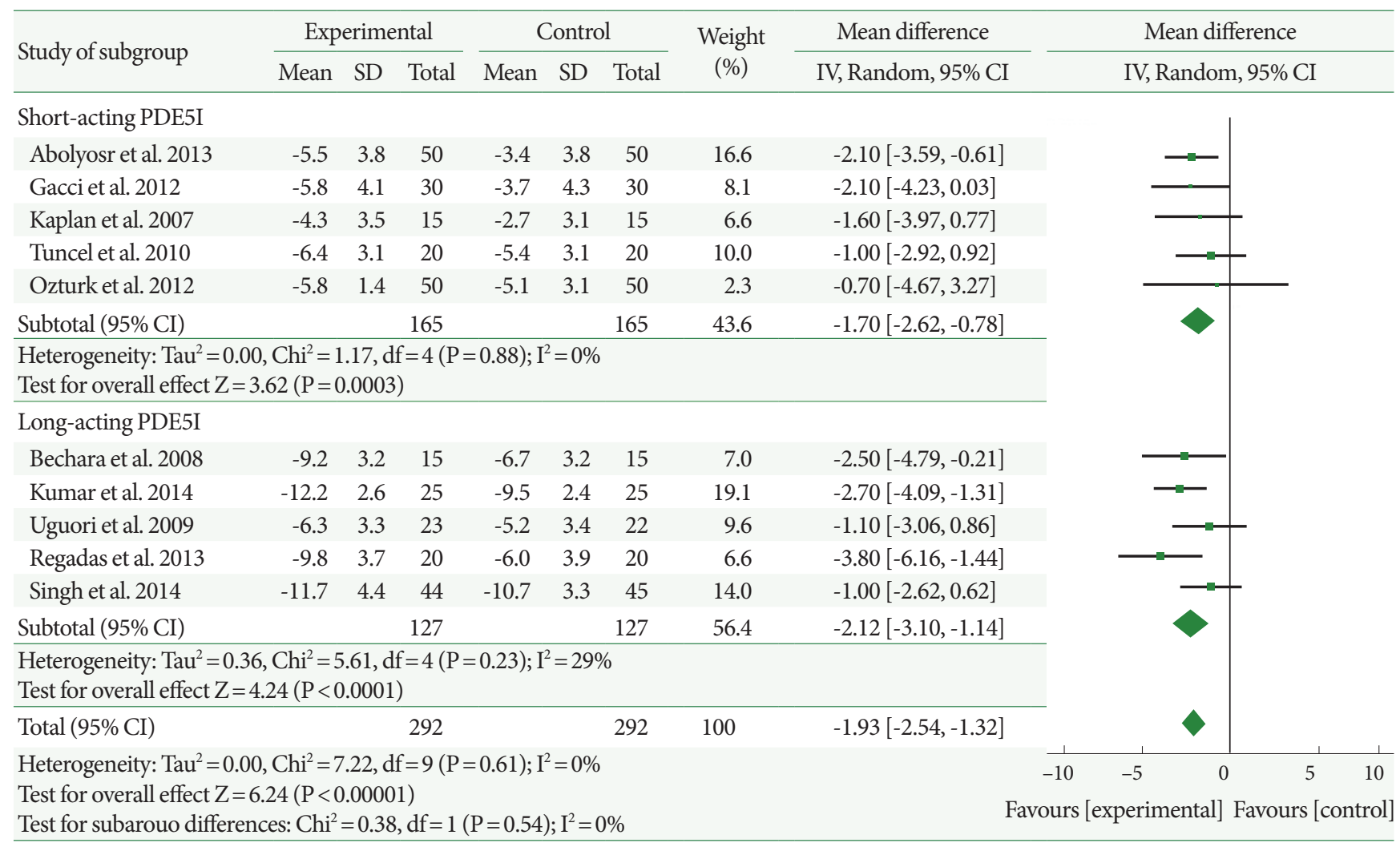

Fig. 2. Weighted differences with 95\% confidence interval (CI) of International Prostate Symptom Score between phosphodiesterase type 5 inhibitors (PDE5Is) plus $\alpha$-1-adrenergic blocker (experiment ) vs. $\alpha$-1-adrenergic blocker alone (control). SD, standard deviation; $\mathrm{df}$, degrees of freedom; IV, inverse variance.

PDE5I of -2.12 vs. -1.70 , respectively; however, this difference was not statistically significant.

The Qmax increased more in the combination therapy-treated patients than it did in those administered $\alpha$-1-adrenergic blocker monotherapy, with a mean difference of 0.71 ( $95 \% \mathrm{CI}$, 0.08-1.33). Furthermore, the mean Qmax change of the longacting PDE5Is was 0.14, which was not increased more significantly with combination therapy than with $\alpha$-1-adrenergic blocker monotherapy. However, combination therapy with short-acting PDE5Is significantly increased the Qmax by 1.13 compared with $\alpha$-1-adrenergic blocker monotherapy (Fig. 3).

In Fig. 4, the residual urine decreased more in patients administered combination therapy than those administered $\alpha-1$ adrenergic blocker monotherapy with a mean difference of -7.09 (95\% CI, -13.15 to -1.04 ). Furthermore, the mean residual urine change values with long- vs. short-acting PDE5Is were -18.83 vs. -5.93 , respectively; however, this difference was not statistically significant. In addition, the heterogeneity was high with the long-acting PDE5Is $\left(I^{2}=86 \%\right)$.
Finally, the International Index of Erectile Function (IIEF) increased more in patients administered combination therapy than in those administered $\alpha$-1-adrenergic blocker monotherapy, with a mean increment of 3.99 (95\% CI, 2.42-5.56). Interestingly, the mean IIEF improvement of the long-acting PDE5I combination therapy was less than that short-acting PDE5I (2.85 and 4.85, respectively) but with negligible differences. Furthermore, the heterogeneity was high with both long- and short-acting PDE5Is ( $\mathrm{I}^{2}=77 \%$ and $75 \%$, respectively; Fig. 5).

\section{DISCUSSION}

There are established associations between ED and LUTS involving several pathways. Therefore, although PDE5Is have been developed for the treatment of ED, they have positive effects in reducing the severity of LUTS that are mainly mediated through the NO pathway, which facilitates the relaxation of the prostate and bladder smooth muscles.

NO synthase has the most critical role in the erection process 


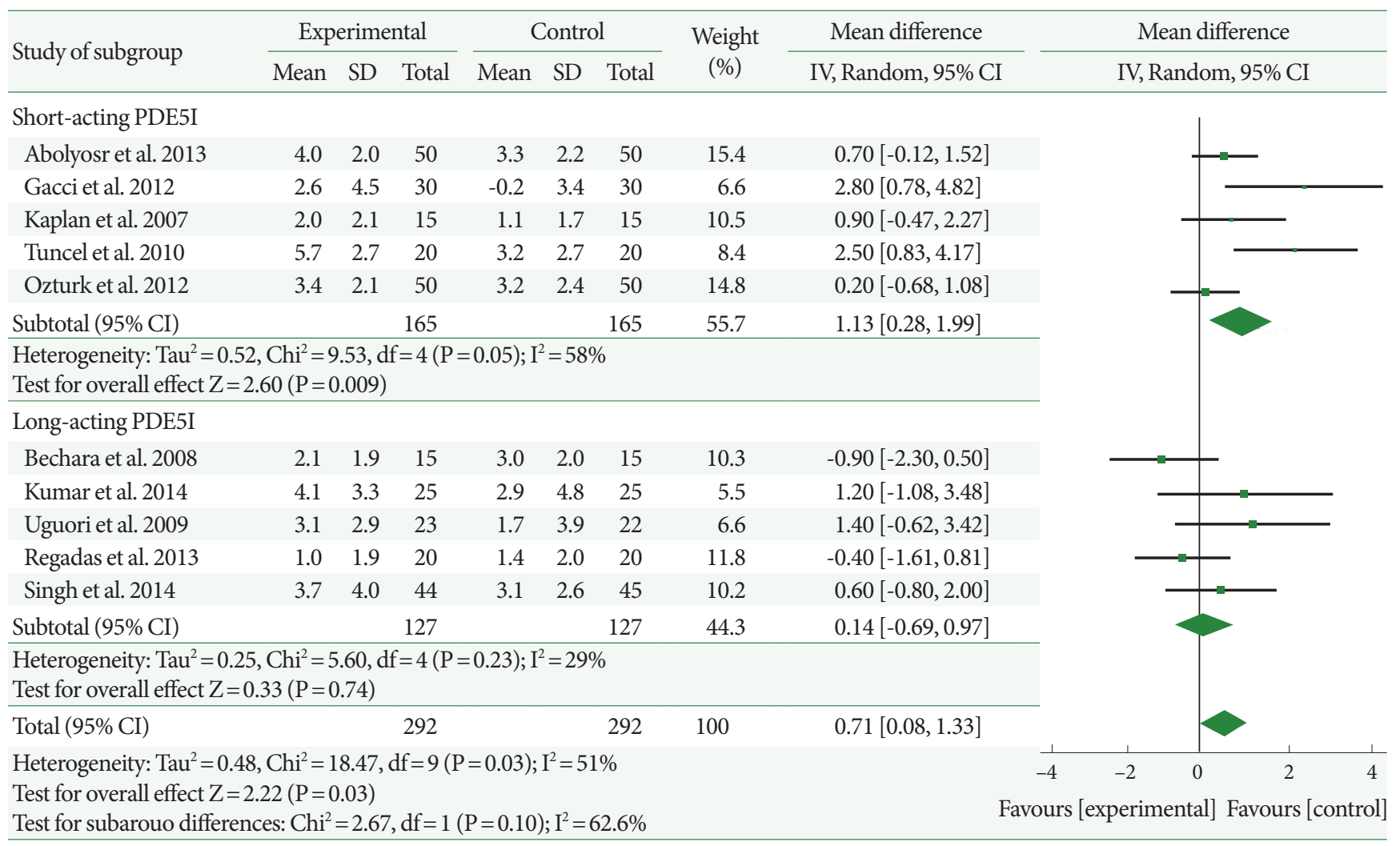

Fig. 3. Weighted differences with $95 \%$ confidence interval (CI) of maximum flow rate between phosphodiesterase type 5 inhibitors (PDE5Is) plus $\alpha$-1-adrenergic blocker (experiment) vs. $\alpha$-1-adrenergic blocker alone (control). SD, standard deviation; df, degrees of freedom; IV, inverse variance.

by increasing the intracellular cGMP level of the smooth muscle in the penis via guanylate cyclase activation, thereby triggering penile erection by relaxation. PDEIs increase the cellular cGMP concentration and reduce the smooth muscle tone in the prostate and urethra.

Among the 11 types of PDEs, PDE4 and 5 are comparatively more highly expressed in the prostate than in other tissues, and NO may act on the prostate in particular. Male sexual organ dysfunctions are often caused by changes in the NO system in the pelvic cavity and reduced relaxation due to decreased NO in smooth muscle tissue within the prostate. Therefore, PDE5Is might enhance recovery from impairment caused by LUTS [10]. A recent study on the daily administration of low-dose PDE5I indicated that the concomitant use of $\alpha$-blockers and PDE5Is showed a positive effect on voiding symptoms as well as improvement in the sexual function. This was the first review on the use of PDE5I monotherapy vs. a placebo in LUTS/BPH and the authors concluded that PDE5Is are effective, safe, and could be used as initial treatment for LUTS/ED [11]. Another systematic review that excluded meta-analysis reported that PDE5Is alone significantly improved both urinary and erectile function without a change in urinary flow rate [12].

Finally, a descriptive analysis examining the role of combined PDE5Is and $\alpha$-blocker therapy reported a significant improvement in voiding symptoms with no proof of positive effects on urodynamic parameters [13]. Moreover, our meta-analysis of the combination therapy (PDE5Is plus $\alpha$-blockers) vs. $\alpha$-blockers showed mean differences in the following parameters: IPSS, -1.93 point; Qmax, $0.71 \mathrm{~mL} / \mathrm{sec}$; residual urine, $-7.09 \mathrm{~mL}$; and IIEF, 3.99. All the parameters were relevant in proving the superiority of the clinical efficacy of PDE5Is plus a-blockers over a-blocker monotherapy in improving LUTS.

Currently, several well-known first-line medication options are available for ED, which include PDE5Is with different characteristics such as bioavailability, clinical efficacy, and safety profiles. It has been postulated that the retention of PDE5Is in tissues and not only in the blood would enhance their pharmacological effects, and lead to a persistent erectile action even af- 


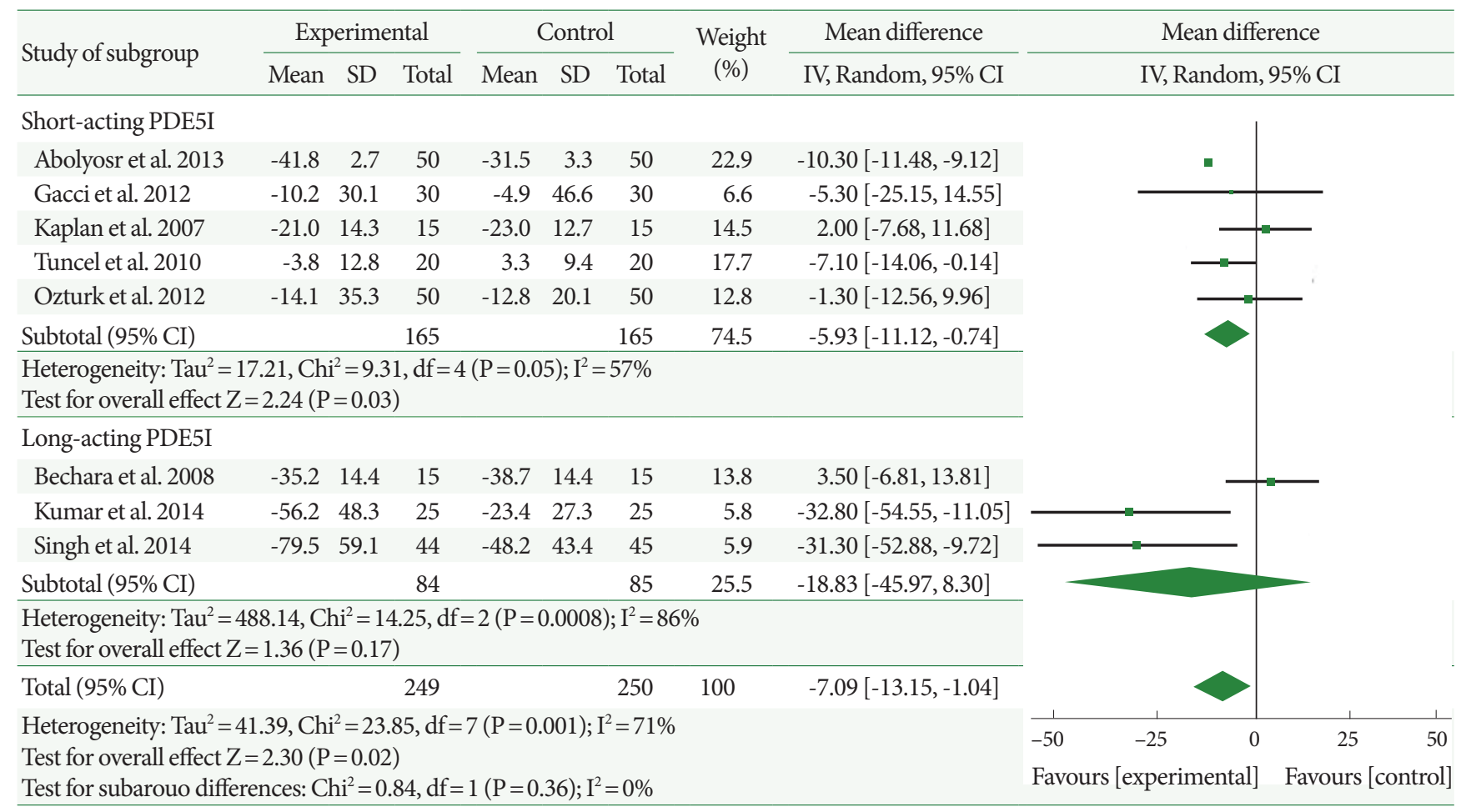

Fig. 4. Weighted differences with $95 \%$ confidence interval (CI) of residual urine between phosphodiesterase type 5 inhibitors (PDE5Is) plus $\alpha$-1-adrenergic blocker (experiment) vs. $\alpha$-1-adrenergic blocker alone (control). SD, standard deviation; df, degrees of freedom; IV, inverse variance.

ter serum levels have diminished below the therapeutic level [14].

Tadalafil appeared in the clinic after sildenafil and vardenafil and attains its peak plasma level within 2 hours, which is relatively later than the $<1$ hour observed with the other PDE5Is [15]. Moreover, the elimination time of the drug effect has been reported to be more than 18 hours because of its low volume of distribution and prolonged clearance by the liver. Therefore, the pharmacological activity of tadalafil persists for up to 36 hours. Although these are apparently superior metabolic characteristics, there is little evidence that these effects can lead to clinical benefits. In fact, our data reveals that the mean IPSS change difference values of the long- vs. short-acting PDE5Is were -2.12 vs. -1.70 , respectively while the residual urine changes were -18.83 vs. -5.93 , respectively. These data suggest that the effects observed were better with the long-acting than they were with the short-acting PDE5I but without statistical significance. However, the mean Qmax change of the long-acting PDE5Is was not significantly improved. The clinical action of the PDE5Is differs from that of $\alpha$-blockers that relax the prostate tension. However, the action of the PDE5Is involves direct re- laxation of the smooth muscle tension in the bladder as well as the prostate and, therefore, the improvement in Qmax is not directly suggestive of clinically superior efficacy [16]. Nevertheless, the IIEF increment of the long-acting PDE5I combination therapy (2.85) was below our expectation. In our opinion, the superior IIEF improvement exhibited by the short-acting PDE5I medication (4.85) may be attributable to the propensity of the patient administered short-acting drugs to be more careful in taking medications and promptly engage in sexual activities. These effects were also caused by an improvement in the endothelial function and continuous oxygenation of the penile tissues. For example, although sildenafil has a relatively short half-life, daily treatment with this drug induced numerous endothelial biological markers that have been identified to enhance the erection process [17]. Furthermore, preceding animal data found that the differences in the concentrations of PDE5Is in the serum and the corpus cavernosum did not correlate with the pharmacokinetic parameters. Consequently, several studies on the effects of PDE5I for the treatment of LUTS cannot be analyzed based on individual serum concentration or half-life of the agent [18]. 


\begin{tabular}{|c|c|c|c|c|c|c|c|c|c|c|c|}
\hline \multirow{3}{*}{$\begin{array}{l}\text { Study of subgroup } \\
\text { Short-acting PDE5I }\end{array}$} & \multicolumn{3}{|c|}{ Experimental } & \multicolumn{3}{|c|}{ Control } & \multirow{2}{*}{$\begin{array}{l}\text { Weight } \\
\text { (\%) }\end{array}$} & \multirow{2}{*}{$\begin{array}{c}\text { Mean difference } \\
\text { IV, Random, 95\% CI }\end{array}$} & \multirow{2}{*}{\multicolumn{3}{|c|}{$\begin{array}{c}\text { Mean difference } \\
\text { IV, Random, 95\% CI }\end{array}$}} \\
\hline & \multirow[t]{2}{*}{ Mean } & \multirow[t]{2}{*}{$\mathrm{SD}$} & \multirow[t]{2}{*}{ Total } & \multirow[t]{2}{*}{ Mean } & \multirow[t]{2}{*}{$\mathrm{SD}$} & \multirow[t]{2}{*}{ Total } & & & & & \\
\hline & & & & & & & & & & & \\
\hline Abolyosr et al. 2013 & 4.6 & 4.1 & 50 & 2.0 & 4.1 & 50 & 12.9 & $2.60[0.99,4.21]$ & & $\longrightarrow$ & \\
\hline Gacci et al. 2012 & 2.6 & 4.0 & 30 & 0.1 & 5.1 & 30 & 11.3 & $2.50[0.18,4.82]$ & & & \\
\hline Kaplan et al. 2007 & 9.5 & 3.7 & 15 & 2.9 & 3.9 & 15 & 10.3 & $6.60[3.88,9.32]$ & & & \\
\hline Tuncel et al. 2010 & 8.1 & 3.0 & 20 & 1.4 & 3.2 & 20 & 12.2 & $6.70[4.78,8.62]$ & & & \\
\hline Ozturk MI et al. 2012 & 8.0 & 6.9 & 50 & 1.7 & 7.0 & 50 & 10.3 & $6.30[3.58,9.02]$ & & & \\
\hline Subtotal (95\% CI) & & & 165 & & & 165 & 57.0 & $4.85[2.81,6.88]$ & & & \\
\hline $\begin{array}{l}\text { Heterogeneity: } \text { Tau }^{2}=4 \\
\text { Test for overall effect } Z=\end{array}$ & $\begin{array}{l}\mathrm{Chi}^{2}=1 \\
67(\mathrm{P}<0 .\end{array}$ & $\begin{array}{l}7.22, \\
.0000\end{array}$ & $\begin{array}{l}\mathrm{df}=4(\mathrm{P} \\
1)\end{array}$ & $=0.002)$ & $; I^{2}=7$ & $77 \%$ & & & & & \\
\hline Long-acting PDE5I & & & & & & & & & & & \\
\hline Bechara et al. 2008 & 8.2 & 3.5 & 15 & 1.9 & 3.4 & 15 & 10.9 & $6.30[3.83,8.77]$ & & & \\
\hline Kumar et al. 2014 & 4.3 & 7.1 & 25 & 2.3 & 7.2 & 25 & 7.7 & $2.00[-1.96,5.96]$ & & & \\
\hline Liguori et al. 2009 & 5.3 & 3.5 & 23 & 4.6 & 3.6 & 22 & 11.8 & $0.70[-1.38,2.78]$ & & & \\
\hline Singh et al. 2014 & 6.4 & 4.4 & 44 & 4.0 & 4.0 & 45 & 12.6 & $2.40[0.65,4.15]$ & & - & \\
\hline Subtotal $(95 \%$ CI) & & & 107 & & & 107 & 43.0 & $2.85[0.46,5.24]$ & & & \\
\hline $\begin{array}{l}\text { Heterogeneity: } \mathrm{Tau}^{2}=4 \\
\text { Test for overall effect } \mathrm{Z}=\end{array}$ & $\begin{aligned} \mathrm{Chi}^{2} & =1 \\
33(\mathrm{P} & =0\end{aligned}$ & $\begin{array}{l}1.96, \\
.02)\end{array}$ & $f=3(P$ & $=0.008$ & 7 & $75 \%$ & & & & & \\
\hline Total $(95 \%$ CI $)$ & & & 272 & & & 272 & 100 & $3.99[2.42,5.56]$ & & & \\
\hline $\begin{array}{l}\text { Heterogeneity: } \mathrm{Tau}^{2}=4 \\
\text { Test for overall effect } \mathrm{Z}=\end{array}$ & $\begin{array}{l}\mathrm{Chi}^{2}=3 \\
98(\mathrm{P}<0 .\end{array}$ & $\begin{array}{l}5.14, \\
.0000\end{array}$ & lf $=8(P$ & $<0.0001$ & ); $\mathrm{I}^{2}=$ & & & & $\frac{1}{-10}$ & 0 & 10 \\
\hline Test for subarouo differ & & & & & & & & & Favours [control] & Favours [exp & nental] \\
\hline
\end{tabular}

Fig. 5. Weighted differences with 95\% confidence interval (CI) of International Index of Erectile Function score between phosphodiesterase type 5 inhibitors (PDE5Is) plus $\alpha$-1-adrenergic blocker (experiment) vs. $\alpha$-1-adrenergic blocker (control).

Tadalafil is approved for daily administration in the treatment of these conditions and is currently the most popularly used agent, although udenafil daily dosing is now clinically available in Korea. Furthermore, only tadalafil has been approved for the secondary treatment of LUTS and is the most suitable agent because of its pharmacological properties. In our systematic review of the PDE5Is comparing their combination use with $\alpha$-blockers and $\alpha$-blocker monotherapy, several clinics have reported that PDE5Is can improve BPH-related LUT/ED more efficiently.

Previous research studies have already revealed that adverse events involving therapy with PDE5Is plus $\alpha$-blockers were clinically insignificant. Although this review does not include the safety profile, the combination of PDE5Is and a-blockers was tolerable and acceptable as a treatment regimen for men with LUTS and ED [19,20]. Furthermore, there was little discrepancy in the outcome between long- and short-acting PDE5Is, which both showed comparable and clear improvement in LUTS/ED in numerous randomized placebo-controlled studies.

Men with LUTS secondary to BPH tend to seek medical help for chronic, senile problems such as ED. This current review has several limitations, which are worth mentioning. There were methodological limits in confirming the individual papers adherence to the inclusion and exclusion criteria, as well as potential publication bias. Furthermore, the heterogeneity of the data were essential problems and safety analyses are lacking. Our data revealed that the mean differences were minimal between the long- and short-acting PDE5Is. However, each arithmetical differences contained some methodological limitations and, therefore, further investigations of related topics would be necessary in future.

Finally, although our review does not contain long-term data, any combination of the PDE5Is with the $\alpha$-1-adrenergic blockers, irrespective of the duration of action, can provide more potent options to improving coexisting LUTS/BPH as well as modify sexual function.

\section{REFERENCES}

1. Jacobsen SJ, Jacobson DJ, Girman CJ, Roberts RO, Rhodes T, Guess $\mathrm{HA}$, et al. Natural history of prostatism: risk factors for acute uri- 
nary retention. J Urol 1997;158:481-7.

2. Norman RW, Nickel JC, Fish D, Pickett SN. 'Prostate-related symptoms' in Canadian men 50 years of age or older: prevalence and relationships among symptoms. Br J Urol 1994;74:542-50.

3. Andersson KE, de Groat WC, McVary KT, Lue TF, Maggi M, Roehrborn CG, et al. Tadalafil for the treatment of lower urinary tract symptoms secondary to benign prostatic hyperplasia: pathophysiology and mechanism(s) of action. Neurourol Urodyn 2011;30:292-301.

4. Hellstrom WJ, Sikka SC. Effects of acute treatment with tamsulosin vs. alfuzosin on ejaculatory function in normal volunteers. J Urol 2006;176(4 Pt 1):1529-33.

5. Francis SH, Blount MA, Zoraghi R, Corbin JD. Molecular properties of mammalian proteins that interact with cGMP: protein kinases, cation channels, phosphodiesterases, and multi-drug anion transporters. Front Biosci 2005;10:2097-117.

6. AUA guideline on management of benign prostatic hyperplasia (2003). Chapter 1: Diagnosis and treatment recommendations. AUA Practice Guidelines Committee. J Urol 2003;170(2 Pt 1):53047.

7. Higgins JP, Green S, editors. Cochrane handbook for systematic reviews of interventions. version 5.1.0 [Internet]. The Cochrane Collaboration, 2011 [uptated 2011 Mar; cited 2015 Sep 12]. Available from: http://handbook.cochrane.org.

8. Jadad AR, Moore RA, Carroll D, Jenkinson C, Reynolds DJ, Gavaghan DJ, et al. Assessing the quality of reports of randomized clinical trials: is blinding necessary? Control Clin Trials 1996;17:112.

9. Schulz KF, Altman DG, Moher D; CONSORT Group. CONSORT 2010 Statement: updated guidelines for reporting parallel group randomised trials. BMC Med 2010;8:18.

10. Uckert S, Oelke M, Stief CG, Andersson KE, Jonas U, Hedlund P. Immunohistochemical distribution of cAMP- and cGMP-phosphodiesterase (PDE) isoenzymes in the human prostate. Eur Urol 2006;49:740-5.

11. Liu L, Zheng S, Han P, Wei Q. Phosphodiesterase-5 inhibitors for lower urinary tract symptoms secondary to benign prostatic hyperplasia: a systematic review and meta-analysis. Urology 2011; 77:123-9.

12. Laydner HK, Oliveira P, Oliveira CR, Makarawo TP, Andrade WS, Tannus M, et al. Phosphodiesterase 5 inhibitors for lower urinary tract symptoms secondary to benign prostatic hyperplasia: a systematic review. BJU Int 2011;107:1104-9.

13. Martínez-Salamanca JI, Carballido J, Eardley I, Giuliano F, Gratzke $\mathrm{C}$, Rosen $\mathrm{R}$, et al. Phosphodiesterase type 5 inhibitors in the man- agement of non-neurogenic male lower urinary tract symptoms: critical analysis of current evidence. Eur Urol 2011;60:527-35.

14. Sommer F, Klotz T, Engelmann U. Improved spontaneous erectile function in men with mild-to-moderate arteriogenic erectile dysfunction treated with a nightly dose of sildenafil for one year: a randomized trial. Asian J Androl 2007;9:134-41.

15. Forgue ST, Patterson BE, Bedding AW, Payne CD, Phillips DL, Wrishko RE, et al. Tadalafil pharmacokinetics in healthy subjects. Br J Clin Pharmacol 2006;61:280-8.

16. Fibbi B, Morelli A, Vignozzi L, Filippi S, Chavalmane A, De Vita G, et al. Characterization of phosphodiesterase type 5 expression and functional activity in the human male lower urinary tract. J Sex Med 2010;7(1 Pt 1):59-69.

17. Gacci M, Salvi M, Sebastianelli A, Vignozzi L, Corona G, McVary $\mathrm{KT}$, et al. The use of a single daily dose of tadalafil to treat signs and symptoms of benign prostatic hyperplasia and erectile dysfunction. Res Rep Urol 2013;5:99-111.

18. Konstantinopoulos A, Giannitsas K, Athanasopoulos A, Spathas D, Perimenis $P$. The impact of daily sildenafil on levels of soluble molecular markers of endothelial function in plasma in patients with erectile dysfunction. Expert Opin Pharmacother 2009;10:155-60.

19. Kaplan SA, Gonzalez RR, Te AE. Combination of alfuzosin and sildenafil is superior to monotherapy in treating lower urinary tract symptoms and erectile dysfunction. Eur Urol 2007;51:1717-23.

20. Bechara A, Romano S, Casabe A, Haime S, Dedola P, Hernandez C, et al. Comparative efficacy assessment of tamsulosin vs. tamsulosin plus tadalafil in the treatment of LUTS/BPH. Pilot study. J Sex Med 2008;5:2170-8.

21. Liguori G, Trombetta C, De Giorgi G, Pomara G, Maio G, Vecchio $D$, et al. Efficacy and safety of combined oral therapy with tadalafil and alfuzosin: an integrated approach to the management of patients with lower urinary tract symptoms and erectile dysfunction. Preliminary report. J Sex Med 2009;6:544-52.

22. Tuncel A, Nalcacioglu V, Ener K, Aslan Y, Aydin O, Atan A. Sildenafil citrate and tamsulosin combination is not superior to monotherapy in treating lower urinary tract symptoms and erectile dysfunction. World J Urol 2010;28:17-22.

23. Gacci M, Vittori G, Tosi N, Siena G, Rossetti MA, Lapini A, et al. A randomized, placebo-controlled study to assess safety and efficacy of vardenafil $10 \mathrm{mg}$ and tamsulosin $0.4 \mathrm{mg}$ vs. tamsulosin $0.4 \mathrm{mg}$ alone in the treatment of lower urinary tract symptoms secondary to benign prostatic hyperplasia. J Sex Med 2012;9:1624-33.

24. Ozturk MI, Koca O, Sertkaya Z, Keles MO, Kaya C, Karaman MI. Acute effects of sildenafil on uroflowmetric parameters in erectile dysfunction patients with and without lower urinary tract symp- 
toms. J Androl 2012;33:1165-8.

25. Regadas RP, Reges R, Cerqueira JB, Sucupira DG, Josino IR, Nogueira EA, et al. Urodynamic effects of the combination of tamsulosin and daily tadalafil in men with lower urinary tract symptoms secondary to benign prostatic hyperplasia: a randomized, placebo-controlled clinical trial. Int Urol Nephrol 2013;45:39-43.

26. Abolyosr A, Elsagheer GA, Abdel-Kader MS, Hassan AM, AbouZeid AM. Evaluation of the effect of sildenafil and/or doxazosin on Benign prostatic hyperplasia-related lower urinary tract symptoms and erectile dysfunction. Urol Ann 2013;5:237-40.
27. Kumar S, Kondareddy C, Ganesamoni R, Nanjappa B, Singh SK. Randomized controlled trial to assess the efficacy of the combination therapy of Alfuzosin and Tadalafil in patients withlower urinary tract symptoms due to benign prostatic hyperplasia. LUTS 2014;6:35-40.

28. Singh DV, Mete UK, Mandal AK, Singh SK. A comparative randomized prospective study to evaluate efficacy and safety of combination of tamsulosin and tadalafil vs. tamsulosin or tadalafil alone in patients with lower urinary tract symptoms due to benign prostatic hyperplasia. J Sex Med 2014;11:187-96. 